\title{
IS THE SUPPLY CHAIN ORIENTATION IN AN AGILE SUPPLY CHAIN DETERMINING THE SUPPLY CHAIN PERFORMANCE?
}

\section{Thanaporn Sriyakul ${ }^{1}$, Andi Luhur Prianto ${ }^{2}$, Kittisak Jermsittiparsert ${ }^{3}$}

${ }^{1}$ Faculty of Business Administration, Mahanakorn University of Technology, Bangkok, Thailand ${ }^{2}$ Faculty of Social and Political Science, Muhammadiyah University of Makassar, South Sulawesi, Indonesia

${ }^{3}$ Department for Management of Science and Technology Development, Ton Duc Thang University, Ho Chi

Minh City, Vietnam ; Faculty of Social Sciences and Humanities, Ton Duc Thang University, Ho Chi Minh City, Vietnam. Email: ${ }^{1}$ ajbamut@gmail.com, ${ }^{2} l u h u r @$ unismuh.ac.id, ${ }^{3}$ kittisak.jermsittiparsert@tdtu.edu.vn

\section{Article History: Received on $25^{\text {th }}$ February 2019, Revised on $28^{\text {th }}$ April 2019, Published on $25^{\text {th }}$ August 2019}

\begin{abstract}
Purpose: The prime objective of the current study is to investigate the relationship between agile supply chain agility, supply chain performance and the supply chain orientation in Indonesia SMEs. In addition to that the indirect relationship between and among the supply chain orientation, supply chain agility and supply chain performance is examined. Employing the survey-based methodology, the SEM-PLS technique is used to test the hypothesized relationships.
\end{abstract}

Methodology: Current study has used SEM-PLS as a statistical tool to answer the research questions raised in this study and research objectives envisaged in the current study.

Results: The findings of the study have provided support to the theoretical foundation and proposed hypothesis of the current study. Current study will be helpful for policymakers and practitioners in understanding the issues related to supply chain risk, supply chain integration and supply chain agility. In the author's knowledge this is among very few pioneering studies on this issue.

Keywords: Supply chain orientation, Agility, Supply Chain, Indonesia.

\section{INTRODUCTION}

Research scholars have been giving substantial attention to supply chain agility, during recent few decades (Tang and Musa, 2011). Prior research have provided empirical evidence regarding the agile SC relationships as a competitive advantage tool, reducing lead time, value differentiators, and managing uncertainties, leading to enhanced SC performance (Tummala and Schoenherr, 2011; Madhusudhanan, 2018; Manesh et al., 2018). Therefore, success of supply chain is dependent on the ability of adapting stakeholders' interests, using faster means as compared to its competitors.

Integrative efforts of the supply chain members give rise to agility. Such efforts can only be achieved through promoting relationships among the downstream and upstream members of the supply chain. Therefore, a comprehensive customer and supplier view is needed for the value creation of end users. (Zhao et al., 2013) defined integrated entity as a supply chain orientation, using a supply chain perspective. Supply chain orientation supports that all SC members should allocate their skills, capabilities, and resources towards value creation for their customers (Kamalahmadi and Parast, 2016). As a total supply chain subset, every member organization interact with the rest of the subsets, and form an ultimate SC. Supply chain orientation is an antecedent of supply chain performance, connecting various activities of supply chain (Pettit et al., 2013). The literature review has provided considerable evidence that supply chain performance and supply chain orientation are positively related with each other (Colicchia and Strozzi, 2012). Although, a mechanism by which supply chain orientation affects supply chain performance, is still vague. Limited investigation has done on the supply chain orientation and impact of intervening variable on the relation among supply chain performance and orientation, making it an arguable area of research in future studies (Mbogela, 2018; Mbunda-Nekang, 2018; Basheer et al., 2019). This research aims to observe how supply chain orientation influences upon the supply chain performance and agility, where supply chain agility acts like a catalyst in supply chain management as a whole, influencing the customer value.

A theoretical model is proposed for deeply estimating the relation among supply chain agility, performance, and supply chain orientation. In addition, the study proposed a route by which influence on supply chain performance through supply chain orientation is explained in a better through supply chain agility, since it acts as a mediator in the relation among SC performance and orientation (Thun and Hoenig, 2011). Supply chain performance is considered as an overall measure of effective supply chain management in our model. Supply chain performance, an important construct, having parameters such as inventory level, customization, and lead time, which can directly affect the process of value creation.

\section{LITERATURE REVIEW HYPOTHESIS DEVELOPMENT}

\section{Supply Chain Orientation (SCO)}

Supply chain goes in hand with the business processes, even if the management does not acknowledge its significance (Fan et al., 2017). It is necessary to isolate management phenomenology with the supply chain structure. Inter-organizational associations provide the basis for supply chain management and supply chain orientation, therefore, complementary and mutual efforts made by SC members act as the drivers of value creation (Qazi et al., 2018). Both downstream and upstream 
resources flows within the SC causes the establishment of supply chain orientation. Thus, supply chain orientation during the value creation process, recommends viewing customers and suppliers as the strategic SC partners.

Firms possessing supply chain orientation fails to obtain benefits out of them. It can only be possible if all the involved supply chain firms exhibit SCO leading to the supply chain management (Diabat et al., 2012). Viewing customer and supplier as strategic partners comes from the transactional approach, which refers to the on-going transactions within the members of supply chain for achieving collaborations. Making supply chain partnerships result in optimality and value transferring for the customers (Abrahamsson et al., 2015). The transvectional concept has been reiterated and argued to be a long lasting and dynamic phenomenon.

Research studies on business integration within the SC has been the main agenda in the previous supply chain management research (Brusset and Teller, 2017). Relational philosophy is the basic foundation of supply chain orientation, promoting collaboration of processes between the organizations. Supply chain orientation has identified to act as a mediator in the relationship between performance and market orientation (Villar et al., 2014). Organizational performance can be exhibited using customer and supplier orientation, as compared to pure market orientation. Supply chain orientation is considered to be an important supply chain management component (Lin and $\mathrm{Wu}, 2014$ ).

Limited literature is available regarding supply chain orientation (Abrahamsson et al., 2015) No more than 50 studies on supply chain orientation have been published so far. The term supply chain orientation and its definition has been presented in a seminal paper by (Helfat et al., 2009). Design for the measurement scale of supply chain orientation was proposed by (Hafeez et al., 2018) and has been revised in a study. An attitudinal scale with two dimensions has been employed. A few empirical researches regarding scale of supply chain orientation, industry specific research, and its impact on the organizational performance, sustainable supply chain, and interdisciplinary studies are available in the literature (Huo et al., 2014; Lavastre et al., 2014).

\section{Supply Chain Agility (Bustinza et al.)}

Supply chain agility refers to the organizational ability of quickly modifying the operations and tactics with its SC, in order to react to environmental threats, opportunities, and changes (Xu et al., 2014). Research on this area can be divided into two broad groups, i.e. speed and responsiveness of SC and the awareness to change. Agility and flexibility have been distinguished by (Park et al., 2016), they also proposed a supply chain agility framework for future studies. The reach and range of supply chain agility has been considered in study and it is concluded that supply chain agility may have the potential to achieve optimal range. It also varies in its dimensions i.e. from 2-7 (Handfield et al., 2015). Various empirical researches are available in the literature regarding supply chain agility that particularly focuses upon spreading awareness about the role of information in establishing SC relationships between the members (Vanpoucke et al., 2014). Another supply chain agility model has proposed, comprising of collaborative planning, strategic HRM, and virtual integration driven by information technology. (Gligor et al., 2016) observed adaptability and agility as well their effects on organizational performance and product complexity. Agility and flexibility always stay in harmony with each other.

Agility is not possible to achieve without flexibility. A study reported that flexibility and agility are found to be internal and external, respectively (Flynn et al., 2010). Furthermore, a study suggested that both internal and external ability is represented by agility. Agility acts as a mediator in the relationship between organizational performance and flexibility. All the SCA researchers are conducting in the developed economies context. Limited research has been undertaken on the SC agility, in terms of emerging economies, such as India. However, no study attempted to address supply chain agility of manufacturer on the supply chain performance and orientation. In addition, supply chain agility as a mediating variable among supply chain orientation and performance relation, is also unclear (Khan and Wisner, 2019). Therefore, this study aims to abridge the existing gap in the literature.

\section{Supply Chain Performance (SCP)}

The network of SC is a dynamic and complex phenomenon therefore, it is difficult to identify appropriate indicators of supply chain performance. (Tarafdar and Qrunfleh, 2017) proposed a route for enhancing supply chain performance i.e. manufacturing which is expected to link SC objectives with the well-defined SC performance parameters. Figure 2, shows the literature about the measurement of supply chain performance. The conceptual research emphasizes upon prescriptive methodologies and measurement construct, whereas, empirical research emphasizes upon performance content as compared to the measurement process (Chan et al., 2017). However, effectiveness and efficiency are the two common dimensions found in the literature of supply chain performance. In case of supply chain performance, determination problems may exist such as, those variables that are usually employed as a proxy for estimating supply chain performance may fail to cover all the output dimensions. Thus, fill rate of performance could be enhanced by giving time for fully maximizing the trucks' capacity. Therefore, filling rate is considered to be an appropriate proxy for the purpose of transportation cost but is not found to be a good customer service indicator, as higher filling rate increases customers' waiting time.

There are several supply chain performance indicators, mentioned in the literature, such as flexibility and customer service are the estimators of operational performance, competitive priorities namely; quality, speed, flexibility, and cost Indicators of process improvements namely; delivery reliability, lead times, responsiveness, customization, time-to-time markets, and 
cost reduction (Jajja et al., 2018) indicators of financial performance are ROI and ROA, and the customer-performance estimators i.e. reduced carbon emissions (Dubey et al., 2018).

\section{Hypotheses Development}

Empirical evidence is available about the positive association among SC performance and supply chain orientation (Jajja $e t$ al., 2017). Supply chain orientation is declared to be an essential condition for the overall performance and effectiveness of supply chain Adopting supply chain orientation by the members of the SC could result in the downstream and upstream changes of the players, thus affecting the performance of the supply chain, as a whole.

Moreover, supply chain orientation motivates organizations to develop cultural elements such as, support of top management, commitment, trust, and cooperative norms. Contingent analysis related to SCO positively influences the supply chain performance, as the support of top management results in efficient production capacity, firm's resource utilization, and strategic and well-informed decision-making (Jajja et al., 2018). Inter-organizational commitment is found to have positive association with productivity, effectiveness, and efficiency outcomes consequently minimizing the controlling and monitoring costs in the relationship. Inter-organizational compatibility helps in focusing to create value for the customers, therefore enhancing the customer-oriented performance of the firm. In addition, cooperative norms bring efficient experience transferring to new conditions, thus improving the partnership efficiency, relational capital creation, and improving outcomes of supply chain (Yan and Dooley, 2013). Moreover, benevolence helps in achieving joint SC outcomes and enhancing relational performance of partners through encouraging closer relationships, enhanced mutual trust and cooperation within the SC (Handfield et al., 2015) Furthermore, credibility is found to have positive effects on the survival instincts of the SC partners, leading to supply chain growth and profitability (Khan and Wisner, 2019). On the basis of the above discussion, the following hypothesis is proposed:

\section{H1: A positive and significant relation exists between the supply chain performance and supply chain orientation.}

(Jajja et al., 2018) suggested that supply chain agility affects the organizational cost efficiency such as the ability of carrying out supply chain processes through relatively less input resources. Supply chain agility demands specific investments for reaping flexibility and customization benefits and reacting with changing business variations. Therefore, the collaboration among the SC partners, supported by agility, plays its role to prevent them from opportunistic behavior and encourage economizing and transactions on bounded rationality (Dubey et al., 2018). The resource consumption and transaction costs are then decline resulting in higher performance. According to transaction cost economics, minimizing conflicts and uncertainty can improve supply chain performance in the SC partnerships. Supply chain agility via cost efficiency creates SC value similar outcomes can be achieved from transportation or logistics activities for enhancing sales, profits, better customer satisfaction, and inventory turnover. (Jajja et al., 2017) suggests that agility enables cost leveraging and better resource allocation to add values to the final users, thus, results in superior SC performance. Therefore, we hypothesize as

\section{H2: A positive and significant relation exists between supply chain performance and supply chain agility.}

Supply chain orientation refers as a tendency of SC members to take supply chain as some integrated entity as well as fulfilling the requirements of supply chain in an integrated manner (Yan and Dooley, 2013). Such tendency of supply chain orientation is essential as nowadays it is not just firms rather supply chains that are competing with each other, under quickly changing market needs and environment. Therefore, considerable attention has gained by the concept of agility. On the other hand, dynamic capability shows the organizational ability to incorporate, develop, and reconfigure external and internal supply chain competencies for dealing with rapidly changing business conditions. These are higher level competences that are assigned to modify operating routines and patterns enabling organizations to redesign their supply chain resources and invest more in environmental changing demands. Whereas, supply chain agility exhibits such underlying features and calling them as dynamic capabilities that arise from the organizational ability of redesigning supply chain and firm level resources (Hair et al., 2011). Therefore, we propose:

H3: Supply chain agility acts as a mediator in the relation among supply chain orientation and supply chain performance.

\section{METHODOLOGY}

The Study has employed surveys-based method with the aid of a questionnaire. The original questionnaire was worded in English but since the targeted study respondents '(i.e. Libyan bank branch managers) mother tongue is Arabic, it was translated into Arabic language. The translation was carried out through back translation procedure, where the questionnaire was translated into Arabic, and then back to English in order to confirm both validity and reliability of the wording. Two bilinguals 'services were obtained to translate it first into Arabic, and then two others were requested to back translate the translated original version, without confirming with the original version. The two English versions of the questionnaire were then compared after which minor changes were made accordingly. Back translation guarantees the near equivalence of the two English versions of the questionnaire. Data analysis in this study was conducted with the help of the software package, SmartPLS, Version 2.0 M3 as suggested by (Vanpoucke et al., 2014). Smart PLS is extensively utilized in the field of marketing and management science. According to researchers (Henseler et al., 2009), a PLS model is 
generally analyzed and interpreted in two phases; first measuring the outer model for validity and reliability and second, analyzing the structure model by R square, effect size, predictive model relevance, and goodness of fit (GoF). In the first phase, properties of multi-item constructs are measured with the inclusion of convergent validity and discriminant validity. Following the second phase, the study hypotheses testing is conducted through the bootstrapping method. The initial study model comprised reflective measurement items that are manifest variables or indicators, four latent variables including two independent, one dependent variable and one mediating variable constituting direct and indirect relationships between them on the basis of the proposed study. Quite a number of analysis techniques exist in research field. Some of them include, descriptive, factor analysis, correlation analysis, and regression analysis (simple, multiple and hierarchical regressions). Each of these analyses is applied depending on the nature and objective of the study. For this study, various analyses such as descriptive analysis, factor analysis, correlation analysis, multiple and hierarchical regressions were all applied in order to achieve the study objectives. These analyses are briefly discussed below

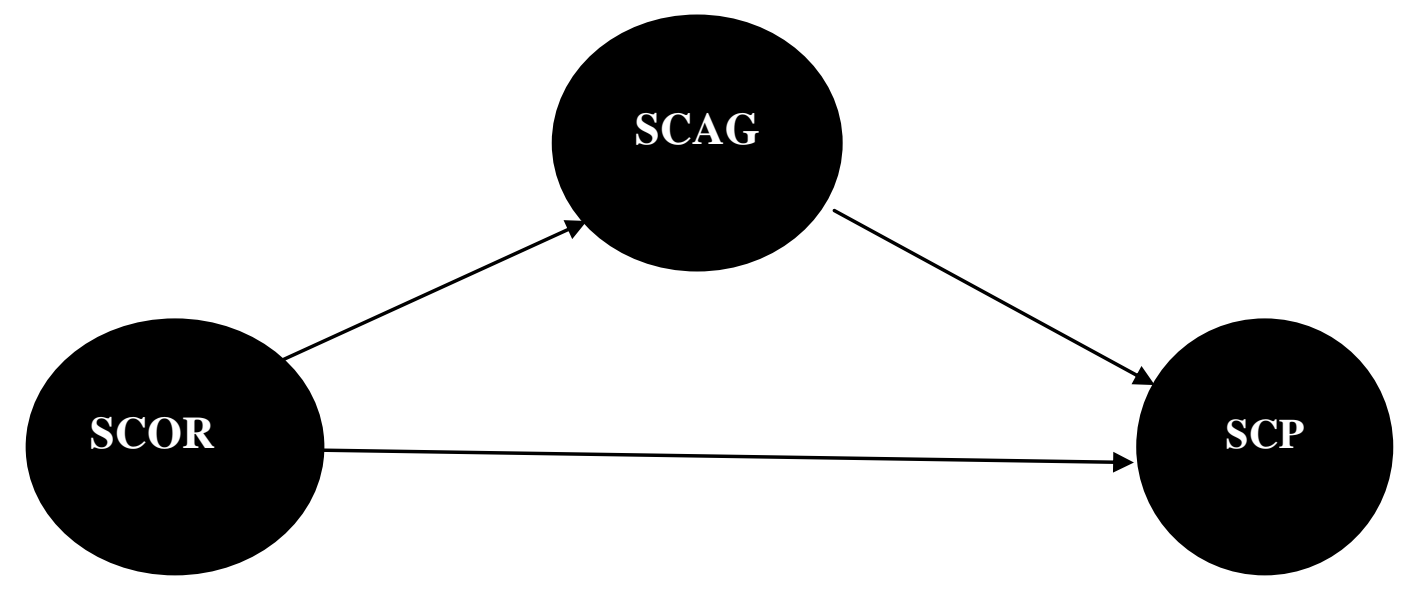

Figure 1: Conceptual Framework

\section{RESULTS}

This analysis was used to establish the nature of the relationship between the independent and dependent variables in this study. Thus, it was used to explain the influence of the independent variables on the dependent variable as theorized in this study. Multiple regressions are used to identify dominant factors amongst the personal and situational characteristics with information sources and channels. The factors are considered dominant if the beta value is the largest among the significant factors. This statistical analysis technique determines the relationship between the relationships between the independent and dependent variables. Therefore, the researchers used this analysis technique to understand the relationship between the independent (x) and dependent variables (y) Researchers can always establish the relationship between the $\mathrm{x}$ and $\mathrm{y}$ through the application of the regression analysis. Hence, this analysis technique assisted this study to determine the relationship between the independent and dependent variables of this study.

CFA is one of the relevant analyses utilized by researchers to determine the number of factors that determine the structure of a variable. It is also very useful in checking the validity of the instrument that will be utilized in the study. Two major forms of factor analysis exist in the area of social science research (Henseler et al., 2009). The exploratory factor analysis is often used to determine the structure of the items while the component factor analysis is also used to reduce the number of the items. They include exploratory and principal component factor analyses. The study employed the component factor analysis technique in order to determine the number of items that loaded on a factor or on the other hand, determine the structure of a variable. Also, it played a very significant role in checking the construct validity of the instrument. So, owing to this, the study conducted a factor analysis in order to determine the number of items loaded on a factor and at the same time checks whether each item measured the variable. In this case, the study used the component factor analysis with a varimax rotation as suggested by (Hair et al., 2011), all items loading the acceptable limit are all accepted while those not loading the minimum standard are dropped. Thus, items that lacked to load meet the minimum acceptable limit are not used for further analysis in this study. In addition to this, the study equally ensured that the result of the factor analysis indicates an Eigenvalue greater than 1.

Construct validation deals with inferences of validity regarding unobserved variables in the form of the construct; having its basis on the observed variables which are presumed indicators. Construct validity was carried out by tackling the following questions: whether the correct constructs have been chosen for the purpose of phenomenal explanation and whether the constructs have been suitably operationalized to represent the constructs? These particular questions are impossible to be wholly determined as it will not substantiate the notion that constructs are valid and have been properly operationalized. A number of different procedures can be carried out to study construct validity comprising discriminant and convergent validities despite the above dilemma. Support for construct validity is manifested only during that time when high correlations are exhibited between the same construct's measures making use of different methods (convergent 
validity) and when low correlations between different constructs' measures are displayed. In line with the notion, the following sections investigate construct validity through convergent as well as discriminant validity

Convergent validity is the type of validity that shows whether there is a relationship between individual scale items. Therefore, in line with the process, it has been claimed that convergent validity can be tested with the help of principal components for EFA. Convergent validity finds out if the associations linking the same factor scales are greater than zero, or high enough to carry out discriminant validity tests. Table in Appendix B shows of indicates convergent validity through data showing the entire loadings from principal component factor analysis as $>=.500$, similar to what was suggested. This indicates that the items chosen in the study have achieved convergent validity.

Table 1. Reliability

\begin{tabular}{c|c|c|c}
\hline & CR & AVE & Cronbach Alpha \\
\hline SCOR & 0.975 & 0.872 & 0.885 \\
\hline SCAC & 0.702 & 0.737 & 0.924 \\
\hline SCP & 0.960 & 0.871 & 0.893 \\
\hline
\end{tabular}

Discriminant validity determines the degree of correlation between different constructs. Low correlations are present if individual constructs are unique and hence possess various dimensions. As a result, correlation matrix approach and EFA can both examine construct validity for determining convergent or discriminant validity. After examining the exploratory factors loading correlation matrix, the results revealed that .586 is the lowest within-factor correlation. These correlations are higher than zero (P 0.833, therefore, the violation is considered as none. (Yan and Dooley, 2013) argued that this number should be less than 50 percent. Since the result showed no violation for comparisons, therefore the present study is said to have achieved discriminant validity.

Table 2: Discriminant Validity

\begin{tabular}{c|c|c|c}
\hline & $\mathbf{1}$ & $\mathbf{2}$ & $\mathbf{3}$ \\
\hline SCOR & $\mathbf{0 . 7 0 9}$ & & \\
\hline SCAC & 0.680 & $\mathbf{0 . 7 2 7}$ & $\mathbf{0 . 7 1 2}$ \\
\hline SCP & 0.657 & 0.676 & \\
\hline
\end{tabular}

The significance of the path coefficients was assessed using the standard bootstrapping procedure, which included 5000 bootstrap samples and 266 cases as recommended.

Table 3. Direct Effect

\begin{tabular}{c|c|c|c|c}
\hline & $\mathbf{( \beta )}$ & SD & T-value & P-Values \\
\hline H1 & 0.342 & 0.165 & 3.234 & 0.000 \\
\hline H2 & 0.451 & 0.221 & 3.345 & 0.000 \\
\hline
\end{tabular}

The mediation is shown in table 4

Table 4. Indirect Effect

\begin{tabular}{c|c|c|c|c}
\hline & $(\boldsymbol{\beta})$ & SD & T-value & P-Values \\
\hline H7 & 0.211 & 0.135 & 3.211 & 0.000 \\
\hline
\end{tabular}

Based on (Hair et al., 2011; Michael et al., 2018; Mikail and Zainol, 2018; Mokgari and Pwaka, 2018) suggestion, researchers who use PLS-SEM should apply measures to indicate the models predictive relevance to evaluate the models quality. This study relies on Stone-Geisser's test of predictive relevance using blindfolding procedures. This test is usually used to assess the goodness-of-fit in PLS-SEM modeling predictive relevance.

\section{CONCLUSION}

This research aims to observe how supply chain orientation influences upon the supply chain performance and agility, where supply chain agility acts like a catalyst in supply chain management as a whole, influencing the customer value.A theoretical model is proposed for deeply estimating the relation among supply chain agility, performance, and supply chain orientation. In addition, the study proposed a route by which influence on supply chain performance through supply chain orientation is explained in a better through supply chain agility, since it acts as a mediator in the relation among SC performance and orientation. Supply chain performance is considered as an overall measure of effective supply chain management in our model. Supply chain performance, an important construct, having parameters such as inventory level, customization, and lead time, which can directly affect the process of value creation. In addition, that with the data of the SMEs in Indonesia the hypothesis are validated. As a whole, the present study aims to present a detailed and novel 
explanation as well as empirical investigation that why supply chain ordination encourages organizations to adopt supply chain agility, with the purpose of improving supply chain performance. The prime objective of the current study is to investigate the relationship between agile supply chain agility, supply chain performance and the supply chain orientation in Indonesia SMEs. In addition to that the indirect relationship between and among the supply chain orientation, supply chain agility and supply chain performance is examined. Employing the survey-based methodology, the SEM-PLS technique is used to test the hypothesized relationships. So, the current study has used SEM-PLS as a statistical tool to answer the research questions raised in this study and research objectives envisaged in the current study. The findings of the study have provided support to the theoretical foundation and proposed hypothesis of the current study. Current study will be helpful for policymakers and practitioners in understanding the issues related to supply chain risk, supply chain integration and supply chain agility. In the author's knowledge this is among very few pioneering studies on this issue. Supply chain orientation is declared to be an essential condition for the overall performance and effectiveness of supply chain Adopting supply chain orientation by the members of the SC could result in the downstream and upstream changes of the players, thus affecting the performance of the supply chain, as a whole. Moreover, supply chain orientation motivates organizations to develop cultural elements such as, support of top management, commitment, trust, and cooperative norms.

\section{REFERENCES}

1. Abrahamsson, S., F. Bertoni, A. Mol and R.I. Martín, 2015. Living with omega-3: New materialism and enduring concerns. Environment and Planning D: Society and Space, 33(1): 4-19. https://doi.org/10.1068/d14086p

2. Basheer, M., M. Siam, A. Awn and S. Hassan, 2019. Exploring the role of tqm and supply chain practices for firm supply performance in the presence of information technology capabilities and supply chain technology adoption: A case of textile firms in pakistan. Uncertain Supply Chain Management, 7(2): 275288.https://doi.org/10.5267/j.uscm.2018.9.001

3. Brusset, X. and C. Teller, 2017. Supply chain capabilities, risks, and resilience. International Journal of Production Economics, 184: 59-68.https://doi.org/10.1016/j.ijpe.2016.09.008

4. Bustinza, O., F. Vendrell Herrero, E. Gomes, E.M. Lafuente González, M. Opazo-Basáez, R. Rabetino and Y. Vaillant, 2018. Product-service innovation and performance: Unveiling the complexities. International journal of business environment, 10(2): 95-11.https://doi.org/10.1504/IJBE.2018.095819

5. Chan, A.T., E.W. Ngai and K.K. Moon, 2017. The effects of strategic and manufacturing flexibilities and supply chain agility on firm performance in the fashion industry. European Journal of Operational Research, 259(2): 486499.https://doi.org/10.1016/j.ejor.2016.11.006

6. Colicchia, C. and F. Strozzi, 2012. Supply chain risk management: A new methodology for a systematic literature review. Supply Chain Management: An International Journal, 17(4): 403418.https://doi.org/10.1108/13598541211246558

7. Diabat, A., K. Govindan and V.V. Panicker, 2012. Supply chain risk management and its mitigation in a food industry. International Journal of Production Research, 50(11): 30393050.https://doi.org/10.1080/00207543.2011.588619

8. Dubey, R., N. Altay, A. Gunasekaran, C. Blome, T. Papadopoulos and S.J. Childe, 2018. Supply chain agility, adaptability and alignment: Empirical evidence from the indian auto components industry. International Journal of Operations \& Production Management, 38(1): 129-148.https://doi.org/10.1108/IJOPM-04-2016-0173

9. Fan, H., G. Li, H. Sun and T. Cheng, 2017. An information processing perspective on supply chain risk management: Antecedents, mechanism, and consequences. International Journal of Production Economics, 185: 63-75.https://doi.org/10.1016/j.ijpe.2016.11.015

10. Flynn, B.B., B. Huo and X. Zhao, 2010. The impact of supply chain integration on performance: A contingency and configuration approach. Journal of operations management, 28(1): 58-

71.https://doi.org/10.1016/j.jom.2009.06.001

11. Gligor, D.M., M.C. Holcomb and J. Feizabadi, 2016. An exploration of the strategic antecedents of firm supply chain agility: The role of a firm's orientations. International Journal of Production Economics, 179: 2434.https://doi.org/10.1016/j.ijpe.2016.05.008

12. Hafeez, M.H., M.F. Basheer, M. Rafique and S.H. Siddiqui, 2018. Exploring the links between tqm practices, business innovativeness and firm performance: An emerging market perspective. Pakistan Journal of Social Sciences (PJSS), 38(2): 485-500.

13. Hair, J.F., C.M. Ringle and M. Sarstedt, 2011. Pls-sem: Indeed a silver bullet. Journal of Marketing Theory and Practice, 19(2): 139-152.https://doi.org/10.2753/MTP1069-6679190202

14. Handfield, R.B., P.D. Cousins, B. Lawson and K.J. Petersen, 2015. How can supply management really improve performance? A knowledge-based model of alignment capabilities. Journal of Supply Chain Management, 51(3): 3-17.https://doi.org/10.1111/jscm.12066

15. Helfat, C.E., S. Finkelstein, W. Mitchell, M. Peteraf, H. Singh, D. Teece and S.G. Winter, 2009. Dynamic 
capabilities: Understanding strategic change in organizations. John Wiley \& Sons.

16. Henseler, J., C.M. Ringle and R.R. Sinkovics, 2009. The use of partial least squares path modeling in international marketing. In: New challenges to international marketing. Emerald Group Publishing Limited: pp: $277-$ 319.https://doi.org/10.1108/S1474-7979(2009)0000020014

17. Huo, B., Y. Qi, Z. Wang and X. Zhao, 2014. The impact of supply chain integration on firm performance: The moderating role of competitive strategy. Supply Chain Management: An International Journal, 19(4): 369384.https://doi.org/10.1108/SCM-03-2013-0096

18. Jajja, M.S.S., K.A. Chatha and S. Farooq, 2018. Impact of supply chain risk on agility performance: the Mediating role of supply chain integration. International Journal of Production Economics, 205: 118138.https://doi.org/10.1016/j.ijpe.2018.08.032

19. Jajja, M.S.S., V.R. Kannan, S.A. Brah and S.Z. Hassan, 2017. Linkages between firm innovation strategy, suppliers, product innovation, and business performance: Insights from resource dependence theory. International Journal of Operations \& Production Management, 37(8): 1054-1075. https://doi.org/10.1108/IJOPM-09-2014$\underline{0424}$

20. Kamalahmadi, M. and M.M. Parast, 2016. A review of the literature on the principles of enterprise and supply chain resilience: Major findings and directions for future research. International Journal of Production Economics, 171: 116-133.https://doi.org/10.1016/j.ijpe.2015.10.023

21. Khan, H. and J.D. Wisner, 2019. Supply chain integration, learning, and agility: Effects on performance. Journal of Operations and Supply Chain Management, 12(1): 14. https://doi.org/10.31387/oscm0360218

22. Lavastre, O., A. Gunasekaran and A. Spalanzani, 2014. Effect of firm characteristics, supplier relationships and techniques used on supply chain risk management (scrm): An empirical investigation on french industrial firms. International Journal of Production Research, 52(11): 3381-3403.https://doi.org/10.1080/00207543.2013.878057

23. Lin, Y. and L.-Y. Wu, 2014. Exploring the role of dynamic capabilities in firm performance under the resourcebased view framework. Journal of business research, 67(3): 407-413.https://doi.org/10.1016/j.jbusres.2012.12.019

24. Madhusudhanan, S., 2018. Gender responsive budgeting: A lesson learned and way forward. International Journal of Applied Economics, Finance and Accounting, 2(1): 27-29.https://doi.org/10.33094/8.2017.2018.21.27.29

25. Manesh, M.H., J.S.K. Singh and I.A.B. Hussain, 2018. Transformational leadership and contextual performance: A quantitative study among nursing staff in kuala lumpur. International Journal of Management and Sustainability, 7(2): 101-112.https://doi.org/10.18488/journal.11.2018.72.101.112

26. Mbogela, C.S., 2018. Determinants of africa-bric countries bilateral trade flows. Economy, 5(1): 40-53. https://doi.org/10.20448/journal.502.2018.51.40.53

27. Mbunda-Nekang, F.M., 2018. Preventing conflict and ensuring national peace through folklore: Option for cameroon. International Journal of English Language and Literature Studies, 7(2): 22-31. https://doi.org/10.18488/journal.23.2018.72.22.31

28. Michael, O., O. Justina and D. Olabode, 2018. Child labour and protection: An exploration of vulnerable children in lagos state, nigeria. Humanities, 6(4): 171-179.https://doi.org/10.18488/journal.73.2018.64.171.179

29. Mikail, A. and Z.A. Zainol, 2018. Conservation of biodiversity in sub sahara africa: Prospecting for genetic resources and traditional knowledge regulation in ethiopia. International Journal of Asian Social Science, 8(9): 725-734.https://doi.org/10.18488/journal.1.2018.88.560.568

30. Mokgari, M.T. and O. Pwaka, 2018. An evaluation of the effectiveness of oversight committees: A case of city of johannesburg, section 79 committees. International Journal of Public Policy and Administration Research, 5(2): 48-67.https://doi.org/10.18488/journal.74.2018.52.48.67

31. Park, K., H. Min and S. Min, 2016. Inter-relationship among risk taking propensity, supply chain security practices, and supply chain disruption occurrence. Journal of Purchasing and Supply Management, 22(2): 120130.https://doi.org/10.1016/j.pursup.2015.12.001

32. Pettit, T.J., K.L. Croxton and J. Fiksel, 2013. Ensuring supply chain resilience: Development and implementation of an assessment tool. Journal of Business Logistics, 34(1): 46-76.https://doi.org/10.1111/jbl.12009

33. Qazi, A., A. Dickson, J. Quigley and B. Gaudenzi, 2018. Supply chain risk network management: A Bayesian belief network and expected utility based approach for managing supply chain risks. International Journal of Production Economics, 196: 24-42.https://doi.org/10.1016/j.ijpe.2017.11.008

34. Tang, O. and S.N. Musa, 2011. Identifying risk issues and research advancements in supply chain risk management. International journal of production economics, 133(1): 2534.https://doi.org/10.1016/j.ijpe.2010.06.013

35. Tarafdar, M. and S. Qrunfleh, 2017. Agile supply chain strategy and supply chain performance: Complementary roles of supply chain practices and information systems capability for agility. International Journal of Production Research, 55(4): 925-938.https://doi.org/10.1080/00207543.2016.1203079

36. Thun, J.-H. and D. Hoenig, 2011. An empirical analysis of supply chain risk management in the german 
automotive industry. International journal of production economics, 131(1): 242-

249.https://doi.org/10.1016/j.ijpe.2009.10.010

37. Tummala, R. and T. Schoenherr, 2011. Assessing and managing risks using the supply chain risk management process (scrmp). Supply Chain Management: An International Journal, 16(6): 474-483. https://doi.org/10.1108/13598541111171165

38. Vanpoucke, E., A. Vereecke and M. Wetzels, 2014. Developing supplier integration capabilities for sustainable competitive advantage: A dynamic capabilities approach. Journal of operations management, 32(7-8): 446461.https://doi.org/10.1016/j.jom.2014.09.004

39. Villar, C., J. Alegre and J. Pla-Barber, 2014. Exploring the role of knowledge management practices on exports: A dynamic capabilities view. International Business Review, 23(1): 38-44. https://doi.org/10.1016/j.ibusrev.2013.08.008

40. Xu, D., B. Huo and L. Sun, 2014. Relationships between intra-organizational resources, supply chain integration and business performance: An extended resource-based view. Industrial Management \& Data Systems, 114(8): 1186-1206.https://doi.org/10.1108/IMDS-05-2014-0156

41. Yan, T. and K.J. Dooley, 2013. Communication intensity, goal congruence, and uncertainty in buyer-supplier new product development. Journal of Operations Management, 31(7-8): 523-

542.https://doi.org/10.1016/j.jom.2013.10.001

42. Zhao, L., B. Huo, L. Sun and X. Zhao, 2013. The impact of supply chain risk on supply chain integration and company performance: A global investigation. Supply Chain Management: An International Journal, 18(2): 115 131.https://doi.org/10.1108/13598541311318773 